\title{
Ordered Silica Particles Made by Nonionic Surfactant for VOCs Sorption
}

\author{
Oumaima Difallah $^{a}$, Hadj Hamaizi* $^{*}$, Maria Dolores Ureña Amate ${ }^{b}$, Maria Del Mar Socias-Viciana ${ }^{b}$ \\ ${ }^{a}$ Department of Chemistry, College of Sciences, University of Oran-1 ABB, P.O. Box 1524, Oran- \\ Menaouer, 31000, Algeria \\ ${ }^{b}$ University of Almeria, La Cañada San Urbano S/N 04120 Almeria, España
}

Received: February 29, 2016; Accepted: May 25, 2017

\begin{abstract}
Adsorption of light organic compounds such acetone, 1-propanol and carbon dioxide was tested by using mesoporous silica materials made from non ionic surfactant with long chain and silica sources as tetraethylorthosilicate TEOS and modified Na-X and Li-A Zeolites. X-ray powder diffraction (XRD), nitrogen adsorption-desorption analysis and scanning electron microscopy (SEM) were applied to characterize the silica particles of a variety prepared samples. Acetone, 1-propanol and $\mathrm{CO}_{2}$ adsorption at $298 \mathrm{~K}$ was evaluated by a volumetric method and indicate a high sorption capacity of organic compounds depending essentially on the porous texture of adsorbents. An adsorption kinetic model was proposed to describe the adsorption of VOCs over template-free mesoporous silica materials. A good agreement with experimental data was found.
\end{abstract}

Keywords: Non ionic surfactant, Mesoporous Silica; Zeolites; Adsorption; VOC's

\section{Introduction}

We present a study of the adsorption kinetics of light organic compounds in a series of samples with different textural parameters. The main objective of this study is to investigate the adsorption properties of silica mesostructures with a view to understand its usefulness as an adsorbent for important light hydrocarbons particularly, C1 (carbon dioxide), C3 (acetone and 1-propanol). Organic solvents are emitted or evaporated into the atmosphere and are the sources of about 40 Vol. \% of the volatile organic compound entering the atmosphere. A lot of methods to treat these organic solvents have been developed by Caroll and Ruddy ${ }^{1}$. Adsorption of these contaminants onto an adsorbents and subsequent desorption for reuse or destruction has been a primary route for purifying polluted air. Among these methods, adsorption method is considered as most promising technology in view point of organic solvent recovery and energy saving ${ }^{2}$. In adsorption process, adsorption efficiency is governed by characteristics of adsorbate and adsorbent. Therefore, it is very important to choose appropriate adsorbent ${ }^{3}$. To well understand the nature of the adsorption process, the influence of pore size, surface properties, pore structure and morphology of the adsorbents on VOCs adsorption has been reported in literature ${ }^{4-6}$. However, most research is focused on investigating the influences of one or two kinds of similar adsorbent on the VOCs adsorption. And few authors have reported the specific impact of pore structure of different kinds of materials in the adsorption/desorption process. Kosuge et al. ${ }^{7}$ have investigated the porous properties of various adsorbents and VOCs adsorption/desorption, just focusing

\footnotetext{
* e-mail: hamaizimizou@yahoo.fr
}

on the pore structure and morphology of mesoporous silica. Therefore, the most research is focused to select the adsorbent with a good stability and regeneration performance recently. Many other porous materials such as zeolites are proposed to be used as adsorbents for VOCs removal ${ }^{8-10}$. Discovered in the early 90's by Kresge et al. ${ }^{11}$ and Beck et al. ${ }^{12}$, ordered mesoporous materials are usually obtained in the presence of surfactants which act as organic structuring agents and molecular inorganic precursors. The interaction between organic and inorganic counter parts leads to the formation fordered hybrid mesophases. Among the ordered mesoporous siliceous materials, there are those that are obtained from non-ionic surfactants such as di-block copolymers $\mathrm{C}_{\mathrm{n}} \mathrm{H}_{2 \mathrm{n}+1}{ }^{-}$ $(\mathrm{EO})_{\mathrm{x}}$ called MSU-X and reported by Bagshaw et al. ${ }^{13}$; Huo et al. ${ }^{14}$; Ryoo et al. ${ }^{15}$ and Richer and Mercier ${ }^{16}$, and whose pore size can reach $10 \mathrm{~nm}$ and wall thickness of about $3 \mathrm{~nm}$. The wormhole channel motif is a potentially important structural feature for favorable adsorption, in part, because channel branching within the framework can facilitate access to reactive sites on the framework walls. HMS (hexagonal Mesoporous Silica) wormhole structures, like MSU-X can also have relatively small fundamental particle sizes $(<200$ $\mathrm{nm}$ ), which result in complementary textural mesoporosity for the more efficient transport of reagents to framework reaction centers as shown by Zhang et al. ${ }^{17}$.

In this work, to further study the effect of porous textural (micro-and mesopores) on the adsorption of acetone, 1-propanol and carbon dioxide, a set of spherical and hexagonal ordered mesoporous silica materials have been synthesized with diblock type copolymers $\mathrm{C}_{\mathrm{n}} \mathrm{H}_{2 \mathrm{n}+1}(\mathrm{EO})_{\mathrm{x}}$ as templating agents using tetraethylorthosilicate and zeolites as silica sources. Adsorption of VOCs is investigated in room temperature 
and the modified Avrami's kinetic equation was applied to determine kinetic's parameters.

\section{Experimental}

\subsection{Chemical materials}

Microporous materials 3A(Li-A; CAS No. 12736-96-8) and 13X (Na-X; CAS No. 63231-69-6) were supplied by Zeochem AG, Switzerland. Commercial zeolites were calcined in air at $823 \mathrm{~K}$ for 6 hours to eliminate organic impurities and used as silica source. Polyoxyethylene (20) oleyl ether $\left(\mathrm{C}_{16}-\mathrm{EO}_{20}\right)$ named Brij ${ }^{\circledR} 98$ has been provided by ACROS Organics Inc. Polyoxyethylene (40) nonylphenyl ether,

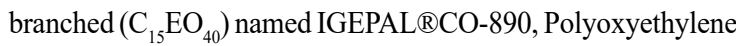
(150) dinonylphenyl ether, branched $\left(\mathrm{C}_{24} \mathrm{EO}_{150}\right)$ named IGEPAL®DM-970, Polyethylene glycol tert-octyl phenyl ether named Triton ${ }^{\mathrm{TM}} \mathrm{X}-100$ and tetraethylorthosilicate (Si$\left.\left(\mathrm{OC}_{2} \mathrm{H}_{5}\right)_{4}\right)$ TEOS were purchased From Aldrich-Sigma, USA. Detailed nomenclature including chemical formulas of the whole surfactants used is given in Table 1. Deionized water and hydrochloric acid $\left(\mathrm{HCl} 1 \mathrm{~mol}^{-1} \mathrm{~L}^{-1}\right)$ have been used for each synthesis; the $\mathrm{HCl} 1 \mathrm{~mol} . \mathrm{L}^{-1}$ was prepared from $37 \%$ fuming hydrochloric acid (Aldrich-Sigma). Volatile compounds such as acetone $\left(\mathrm{M}=58.08 \mathrm{~g} \cdot \mathrm{mol}^{-1}, \mathrm{~T}_{\mathrm{B}}{ }^{\circ} \sim 56-57^{\circ} \mathrm{C}\right), 1$-propanol $\left(\mathrm{M}=60.10 \mathrm{~g} \cdot \mathrm{mol}^{-1}, \mathrm{~T}_{\mathrm{B}}^{\circ} \sim 97-98^{\circ} \mathrm{C}\right)$ purchased by SigmaAldrich, USA and highly pure carbon dioxide (99.99\%) produced by Air Liquide, France, are used for adsorption at room temperature on sorbent materials.

\subsection{Synthesis of sorbents}

Facile protocol of preparation consists in a mixing of an aqueous solution of the surfactant with $\mathrm{HCl} 1 \mathrm{~mol}^{-\mathrm{L}^{-1}}$ solution under constant stirring for 1 hour. The TEOS was added to this mixture and left under stirring for 24 hours at room temperature. The mixture was then heated at $373 \mathrm{~K}$ during 48 hours without stirring. The precipitated solid product was recovered by filtration, washed and dried at $353 \mathrm{~K}$. For example, $2 \mathrm{~g}$ of Brij ${ }^{\circledR} 98$ in $30 \mathrm{~g}$ of demineralized water was stirred for 10 minutes before adding $120 \mathrm{ml}$ of $\mathrm{HCl}$ 1 mol.L $\mathrm{L}^{-1}$ solution. An amount of TEOS $(9 \mathrm{~g})$ was added to this homogeneous mixture and kept under vigorous stirring for
24 hours. The mixture was then introduced into a sealed tube and heated at $373 \mathrm{~K}$ for 48 hours. The resulting precipitated solid product was recovered by filtration, washed and dried. Calcinations of obtained fine white powder was carried out in a tube furnace at $823 \mathrm{~K}$ in air; this temperature was reached with a heating rate of $10 \mathrm{~K} / \mathrm{min}$ and a first plateau at $373 \mathrm{~K}$ for $1 \mathrm{~h}$. After the second plateau at $823 \mathrm{~K}$ for $6 \mathrm{hrs}$, the oven was cooled down at room temperature with a cooling rate of about $5 \mathrm{~K} / \mathrm{min}$. Aluminosilicate framework of both $3 \mathrm{~A}$ and $13 \mathrm{X}$ type zeolite is attacked with a strongly concentrated acid before adding the surfactant. For a type synthesis, $2 \mathrm{~g}$ Brij $^{\circledR} 98$ and $60 \mathrm{~mL} \mathrm{H}_{2} \mathrm{O}$ are mixed with moderate magnetic stirring for $10 \mathrm{~min}$. $60 \mathrm{~mL}$ of $\mathrm{HCl} 1 \mathrm{~mol}^{-\mathrm{L}^{-1}}$ was added drop wise to the solution with the same stirring speed for 60 minutes. Two equal parts of this mixture are separately and simultaneously added to $1 \mathrm{~g}$ of Li-A Zeolite (3A) for one and $1 \mathrm{~g}$ of $\mathrm{Na}-\mathrm{X}$ Zeolite (13X) for the other, with vigorous stirring for 20 hours at room temperature. A heating treatment at $393 \mathrm{~K}$ for 3 days, results in the formation of two distinct phases, which are filtered and dried at $373 \mathrm{~K}$. The stepwise calcinations in air up to $823 \mathrm{~K}$ for 6 hours and gives a fine white powder for both types of zeolites used.

\subsection{Analysis of adsorbents}

Small-angle X-ray diffraction (XRD) patterns were recorded on an Ultima-IV high resolution X-ray powder diffraction (XRD) using $\mathrm{Cu} K \alpha$ radiation $(\lambda=0.15418 \mathrm{~nm})$ in the $2 \theta$ range of $0.5-20^{\circ}$ with a scanning rate of $0.5^{\circ}$ min. The X'PERTPLUS ${ }^{\odot}$ software enabled the counting of the spectra and the calculation of pore-pore distance by indexing the reflections. The $\mathrm{N}_{2}$ isotherms were measured by automated apparatus ASAP 2020 (Micromeritics) at 77K. Prior to $\mathrm{N}_{2}$ adsorption analysis; the samples were degassed at $673 \mathrm{~K}$ under vacuum for 4 hours. The BET surface areas were calculated based on the linear part of the BET plot $\left(P / P_{0}: 0.05-0.35\right)$. The total pore volumes were estimated according to nitrogen uptake at a relative pressure $\left(P / P_{0}\right)$ of ca. 0.990 . The pore size distribution and pore diameter were derived from the desorption branch of the $\mathrm{N}_{2}$ isotherms using Barrett-Joyner-Halenda method using the Halsey equation for multilayer adsorption for all samples. Morphology and particle size of the final products were observed by using

Table 1: Physicochemical properties of surfactants ethers type commercialized under the designation IGEPAL ${ }^{\circledR}$ CO-890, IGEPAL ${ }^{\circledR}$ DM970, Triton ${ }^{\mathrm{TM}} \mathrm{X}-100$ and Brij $^{\circledR} 98$

\begin{tabular}{|c|c|c|c|c|}
\hline Commercial designation & Nomenclature & Chemical formula & Molar weight $/ \mathrm{g} \cdot \mathrm{mol}^{-1}$ & $\operatorname{HLB}(*)$ \\
\hline IGEPAL ${ }^{\circledR}$ DM-970 & $\begin{array}{c}\text { Polyoxyethylene (150) di-nonyl phenyl } \\
\text { ether }\end{array}$ & {$\left[\mathrm{C}_{9} \mathrm{H}_{19}\right]_{2}-\mathrm{C}_{6} \mathrm{H}_{3}-(\mathrm{EO})_{150}-\mathrm{OH}$} & 6946 & 19 \\
\hline IGEPAL $^{\circledR}$ CO-890 & Polyoxyethylene (40) nonylphenyl ether & $\mathrm{C}_{9} \mathrm{H}_{19}-\mathrm{C}_{6} \mathrm{H}_{4-}\left(\mathrm{OC}_{2} \mathrm{H}_{4}\right)_{40-} \mathrm{OH}$ & 1982 & 17 \\
\hline Brij $^{\circledR} 98$ & Polyoxyethylene (20) oleyl ether & $\mathrm{C}_{18} \mathrm{H}_{35-}\left(\mathrm{OC}_{2} \mathrm{H}_{4}\right)_{20-} \mathrm{OH}$ & $\sim 1149$ & 15.3 \\
\hline Triton $^{\mathrm{TM}} \mathrm{X}-100$ & $\begin{array}{c}\text { Polyoxyethylene(10) nonyl cyclohexyl } \\
\text { éther }\end{array}$ & $\mathrm{C}_{14} \mathrm{H}_{21-}\left(\mathrm{OC}_{2} \mathrm{H}_{4}\right)_{10-} \mathrm{OH}$ & $\sim 625$ & 13.5 \\
\hline
\end{tabular}

(*) hydrophilic-lyophilic balance 
scanning electron microscopy FE-SEM (JEOL JSM-6340F) operating at an acceleration voltage of $20-30 \mathrm{kV}$.

\subsection{Adsorption of VOCs}

Adsorption experiments of acetone and 1-propanol were performed by thermogravimetric technique in dynamic mode on a type of unit TGA92 SETARAM. The analyzes were performed on a sample of about $100 \mathrm{mg}$ of material powder. Each analysis starts with an activation phase at $623 \mathrm{~K}$ for one hour with a temperature rise of $5 \mathrm{~K} / \mathrm{min}$ under nitrogen flow. The temperature is then lowered to the analysis temperature (298K). The reactive gas is introduced until the sample material is saturated and the addition of mass change is observed. The material was then regenerated at $623 \mathrm{~K}$ under nitrogen flow. This same technique of thermogravimetry was used to determine the adsorption capacities of silica materials after having contacted $150 \mathrm{~min}$ with the exhaust gas. Adsorption isotherms of $\mathrm{CO}_{2}$ were measured on the same ASAP 2020 (Micromeritics) apparatus at 273K. Sample cell was loaded with ca. $300 \mathrm{mg}$ of the sorbent. Before the sorbent was out gassed in vacuum at $673 \mathrm{~K}$ for $4 \mathrm{~h}$ in order to remove any adsorbed impurities, the adsorption run was carried out using highly pure $\mathrm{CO}_{2}(99.999 \%)$ in a pressure range from 5- 760mm $\mathrm{Hg}$. Maximum amount of adsorbed $\mathrm{CO}_{2}\left(Q_{m}\right)$ was determined by Langmuir equation using molecular cross-sectional area $\left(0.17 \mathrm{~nm}^{2}\right)$ for $\mathrm{CO}_{2}$. We propose also, a general kinetic model to describe the adsorption of $\mathrm{CO}_{2}$ on pure siliceous samples at $0^{\circ} \mathrm{C}$. The equation of adsorption rate at the pseudo-order $n$ purposed by Lagergren ${ }^{18}$ that was used can be expressed in its general form (Eq. (1)):

$$
\frac{\delta q_{t}}{\left(q_{e}-q_{t}\right)^{n}}=k . d t
$$

Where $\mathrm{q}_{\mathrm{e}}$ and $\mathrm{q}_{\mathrm{t}}$ are the sorption capacity at equilibrium and at time, respectively, and $\mathrm{k}$ is the constant rate. This equation stems from the modified Avrami's kinetic equation which implies several steps ${ }^{19}$. Its linear form is deduced by integrating the equation rate (Eq. (2)):

$$
\left(q_{e}-q_{t}\right)^{1-n}=q_{e}^{1-n}+k(n-1) t .
$$

The least squares criterion was used to determine the model parameters. To check the adequacy of the model, the coefficient of correlation $\mathrm{R}^{2}$ between the experimental and calculated data was determined. We have also checked that the value ofcalculated by the theoretical model fit to the experimental value obtained from the Langmuir model applied to adsorption measurements of VOCs at $298 \mathrm{~K}$.

\section{Results and Discussion}

XRD patterns recorded on calcined samples exhibited single broad peak in the $2 \theta$ range of $0.5-3^{\circ}$ (Figure 1 ), indicating a poorly ordered mesostructure lacking long-rang structural order such as observed for mesostructured solids with worm-like pores ${ }^{20}$. According to this XRD most of the prepared silica materials are mesotructured but with a whorm-like mesostructure; pores are regular in terms of size but not spatially ordered. The XRD pattern of TEOS/Brij98 sample shows two peaks which can be indexed in (100) and (200) reflections indicating a 2D hexagonal mesostructure. For the sample denoted 13X/ Brij98, structure is totally modified and becomes amorphous by action of both acid and surfactant, characterized by the presence of a single intense reflection at $2 \theta=1.5^{\circ}$; it is further assumed that all the aluminum of the zeolite crystal structure was dissolved as it has been cited in many studies ${ }^{21-23}$. If the correlation distance deduced from the main XRD peak can be attributed to the pore-pore distance, the calculation gives a value of $43 \AA$ for the modified zeolite, while it is $\sim 54 \AA$ when the TEOS used as silica source, assuming respectively a cubic disposition for the two solids (Table 2).

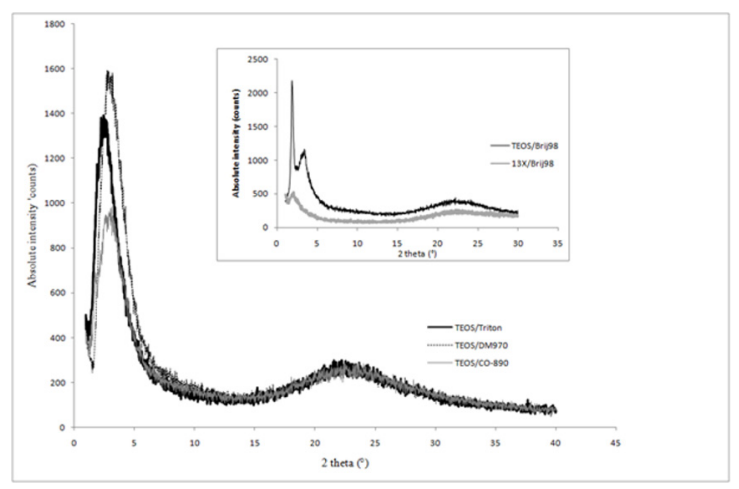

Figure 1. Low-angle XRD patterns of calcined samples

Figure 2 shows the SEM images of calcined samples. Sample of TEOS/Brij98 shows large hexagonal silica assembly with various measurements $(3-7 \mu \mathrm{m})$ and arranged in a tangle from growths on their faces while the sample 13X/Brij98 present aggregates of very small particles which not exceeding $1 \mu \mathrm{m}$. An entangled smalls particles $(<1 \mu \mathrm{m})$ with pseudo cubic shape for samples TEOS/CO-890 and TEOS/DM-970 characterizes the external morphology of silica. External morphology silica particles in both TEOS/ Triton and 3A/Brij98 samples show aggregates composed of smaller particles without distinct shape. Worm-like and hexagonal mesoporous textures are usually observed with such surfactants ${ }^{24}$. 
Table 2: Textural and structural parameters of materials calcined at $550^{\circ} \mathrm{C}$ under air for 6 hours. * used with $30 \mathrm{~g} \mathrm{H}_{2} \mathrm{O} ; 120 \mathrm{ml} \mathrm{HCl} ; 9 \mathrm{~g}$ TEOS. ${ }^{*}$ used with $1 \mathrm{~g}$ of Na-X zeolite. ${ }^{a} d$ value of characteristic reflection of the calcined products. ${ }^{b}$ Calculated at $\mathrm{P} / \mathrm{P}^{\circ}=0.99 ;{ }^{c}$ Pore diameter calculated from desorption branch with $\mathrm{BJH}$ method. ${ }^{d}$ Calculated from $\mathrm{t}=\mathrm{D}_{\text {pore-pore }}-\varnothing$.

\begin{tabular}{|c|c|c|c|c|c|c|c|}
\hline Designation & $\begin{array}{l}\text { Surfactant ma } \\
\text { (duration of synthesi }\end{array}$ & at $273 \mathrm{~K})$ & $\mathrm{D}_{\text {pore-pore }}{ }^{\mathrm{a}} / \mathrm{A}^{\circ}$ & $\mathrm{S}_{\mathrm{BET}} \mathrm{m}^{2} \cdot \mathrm{g}^{-1}$ & $\mathrm{Vp}{ }^{\mathrm{b}} / \mathrm{cm}^{3} \cdot \mathrm{g}^{-1}$ & $\varnothing c / \AA$ & $\begin{array}{c}\text { Wall Thickness } \\
d / \AA\end{array}$ \\
\hline TEOS/DM-970 & 2 g DM-970 & (48h) & 70.6 & 748 & 0.48 & 43.0 & 27.6 \\
\hline TEOS/CO-890 & 2 g CO-890 & $(48 h)$ & 54.8 & 664 & 0.65 & 35.8 & 19.0 \\
\hline TEOS/Brij98 & 2 g Brij98 & $(48 \mathrm{~h})$ & 54.4 & 760 & 0.56 & 43.8 & 10.6 \\
\hline 13X/Brij98 & 2 g Brij98** & $(48 h)$ & 103.8 & 431 & 0.77 & 71.3 & 32.5 \\
\hline TEOS/Triton & $2 \mathrm{~g}$ Triton-X100 & (48h) & 79.8 & 780 & 1.22 & 51.9 & 27.9 \\
\hline
\end{tabular}
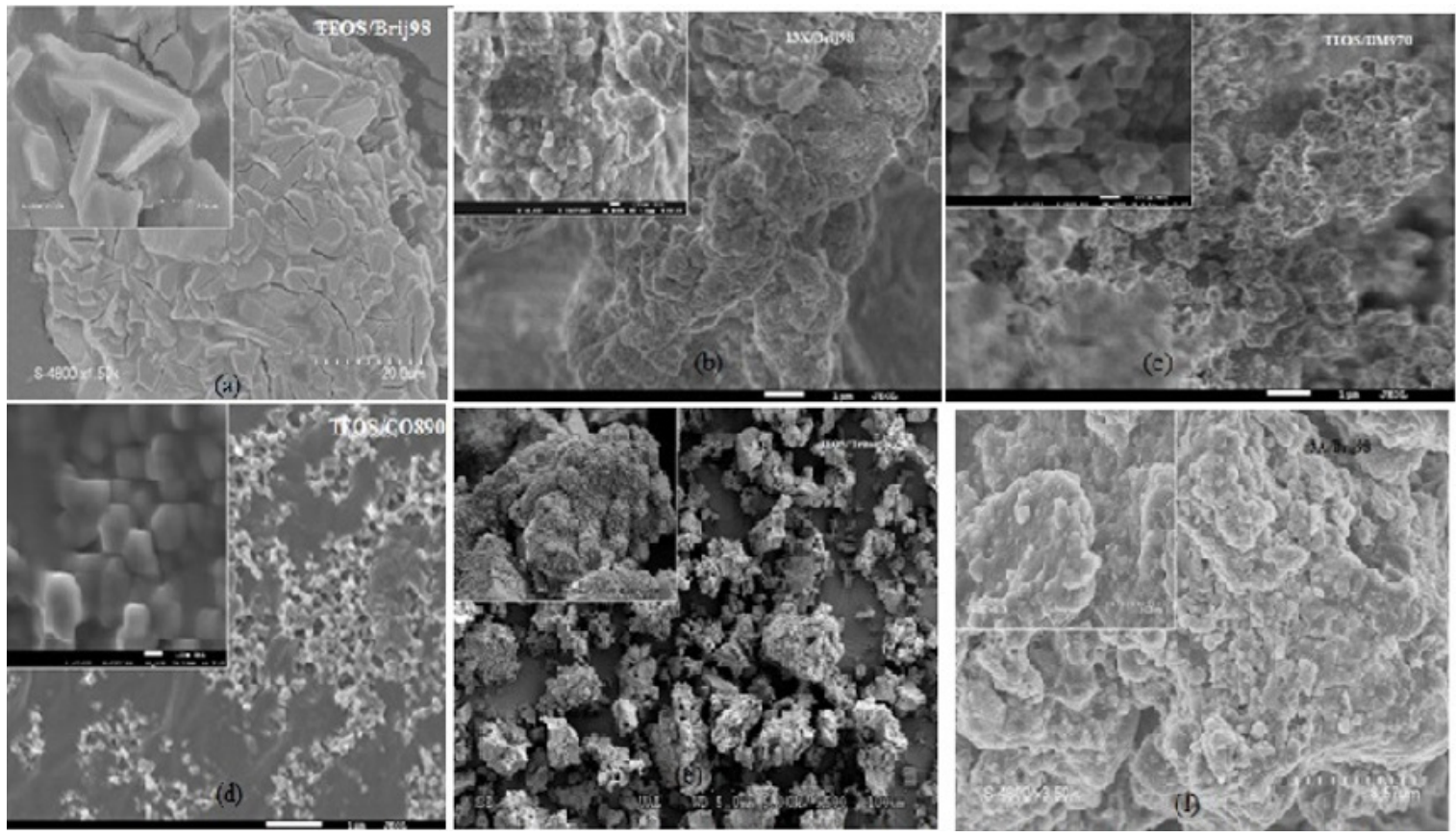

Figure 2. Scanning electron micrographs (SEM) of: TEOS/Brij98 and 13X/Brij98 (top); TEOS/DM-970 and TEOS/CO-890 (bottom).

Nitrogen adsorption/desorption isotherms are type IV for all samples; In Figure 3-A, the shape of the curve differs in desorption branch. Pressures. The hysteresis loop not marked and closes around $P / P_{0}=0.4$ for TEOS/DM970 sample which indicates open pores at their extremities with uniform dimension of approximately $43 \AA$ and having a micro porosity measured at $58 \mathrm{~m}^{2} / \mathrm{g}$ and $0.2 \mathrm{~cm}^{3} / \mathrm{g}$ for surface area and volume. Whereas the one obtained by the Triton-X100 suggests much wider pores. The quantities adsorbed in the TEOS/CO89 sample are also higher whence greater porosity. For this both samples, a rapid increase of the adsorbed amounts is reported by their respective isotherms respectively. Modified zeolite 3A shows a close appearance of the type I showing a horizontal plateau over the whole range, relative and suggests that structure is partially conserved. Thus, there's not much difference in pore sizes, except in 13X/Brij98 which is distinguished by larger pores $(71 \AA)$ greater pore volume $\left(0.77 \mathrm{~cm}^{3} / \mathrm{g}\right)$ and the hysteresis loop of type $\mathrm{H} 2$, characteristic of open pores in the modified zeolite. No micropores observed in the texture showing that practically the crystal lattice of the zeolite original disappeared (figure 3-B). Synthesis with TEOS gives exclusively a mesoporous material as shown in the shape of the isotherm with a slightly marked loop of the hysteresis indicating uniform pores $\left(43.9 \mathrm{~A}^{\circ}\right)$. It would appear that the length of the hydrophilic chain of the surfactant does not necessarily lead to the formation of very large micelles and therefore very large pores considering that the surfactant molecule with a long hydrophilic chain, constituted of many ethylene oxide segments is subject of torsions resulting on size reduction before forming micelles which will have probably almost the same size from the twisted form of the surfactant molecule.

Figure 4 shows the adsorbed quantities of acetone and 1-propanol, indicating rapid adsorption of both volatile which strongly attenuates after $40 \mathrm{~min}$. onto sample TEOS/Brij98, leading to a saturation bearing respectively ca. $170 \mathrm{mg} / \mathrm{g}$ and $130 \mathrm{mg} / \mathrm{g}$ for acetone and alcohol. Filling uniform and 


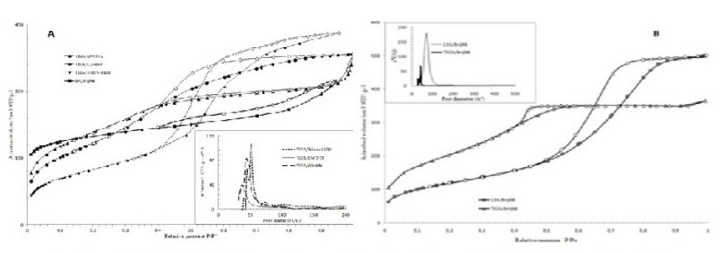

Figure 3. Nitrogen adsorption/desorption isotherms at $77 \mathrm{~K}$ of calcined samples in A: TEOS/DM-970, TEOS/CO-890 and TEOS/Triton-X100; in B: TEOS/Brij98; 13X/Brij98 Insert: pore size distribution (PSD) obtained by BJH method applied on desorption branch.

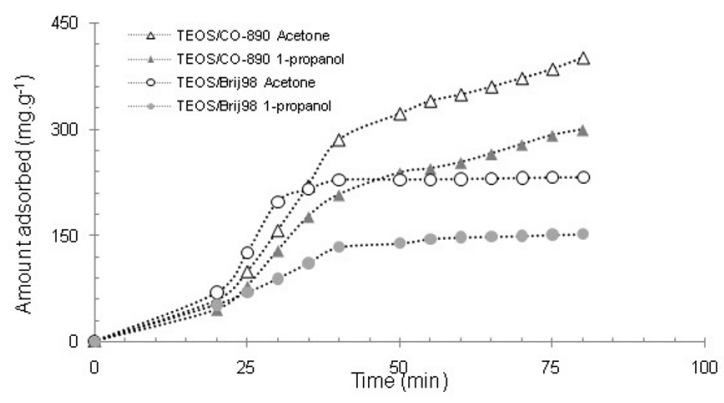

Figure 4. Adsorption breakthrough curves of acetone and 1-propanol over TEOS/CO-890 and TEOS/Brij98

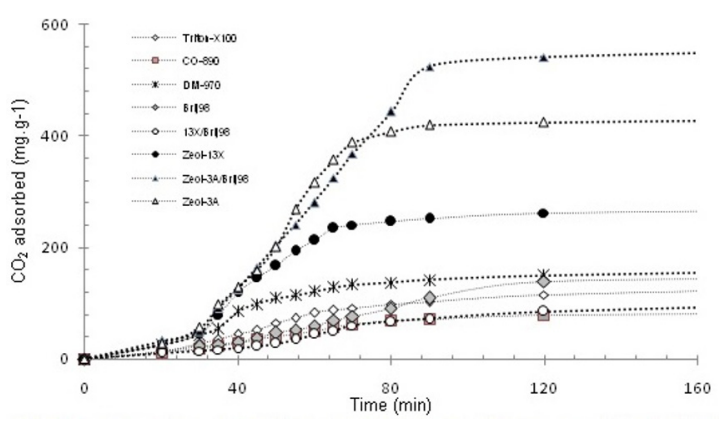

Figure 5. Adsorption breakthrough curves of $\mathrm{CO} 2$ over TEOS/ CO-890; TEOS/DM-970; TEOS/Brij98; 13X/Brij98; TEOS/ Triton-X-100; 3A/Brij98; Zeol-13X and Zeol-3A. regular pores seems to be easier compared to a worm-like arrangement; thus adsorption is even better onto TEOS/ CO-890 material which traps the organic molecule.

Figure 5 indicates the carbon dioxide adsorption breakthrough curves of different adsorbents. The equilibrium times are relatively long at the start of the experiment. Adsorption of the $\mathrm{CO}_{2}$ molecule is carried out slowly at ambient temperature to yield, thereafter the breakthrough curves, S-shaped, with a rapid increase of adsorbed $\mathrm{CO}_{2}$ in a minimum of time before saturation which shows very significant amounts for this purely silica mesoporous. Sample 13X/Brij98 showed a long breakthrough time compared with other porous materials, nearly $40 \mathrm{~min}$.

The shortest breakthrough time, only $10 \mathrm{~min}$. was observed on sample TEOS/DM-970 and we note that $13 \mathrm{X}$, $3 \mathrm{~A}$ zeolites and modified $3 \mathrm{~A}$ material adsorb more $\mathrm{CO}_{2}$ than all others: ca. $680 \mathrm{mg} / \mathrm{g}$ after 100 minutes of contact time for modified $3 \mathrm{~A}$ adsorbent unlike modified $13 \mathrm{X}$ which adsorbs very few $\mathrm{CO}_{2}$. It indicates that absorbents with better porous parameters (surface area and pore volume) do not necessarily show a larger breakthrough capacity. In general, the longer of the breakthrough time indicates a better dynamic adsorption capacity ${ }^{25}$. The modification of $3 \mathrm{~A}$ zeolite by addition of nonionic surfactant offers very high adsorptive capacity, due to the presence of micropores generated by the interconnections of large mesopores unlike modified 13X, which has an exclusively mesoporous texture giving only low amount of adsorbed $\mathrm{CO}_{2}$. The values of the maximum quantity adsorbed for $\mathrm{CO}_{2}$ in this study are comparable to those reported in the literature ${ }^{26-29}: \mathrm{Na}-\mathrm{X}$ (277mg/g; $162 \mathrm{mg} / \mathrm{g})$; Na-Y (184mg/g); Na-A (211mg/g); $5 \mathrm{~A}(50 \mathrm{mg} / \mathrm{g}) ; \mathrm{HMS}(74 \mathrm{mg} / \mathrm{g}) ; \mathrm{MCM}-41(29 \mathrm{mg} / \mathrm{g})$ and active carbon $(396 \mathrm{mg} / \mathrm{g})$.

Table 3: Values of the kinetics model parameters

\begin{tabular}{|c|c|c|c|c|c|c|}
\hline Sample & $\mathrm{n}$ & k (mg.min/g) & $\mathrm{R}^{2}$ & $\mathrm{Q}_{\mathrm{m}}(\mathrm{mg} / \mathrm{g})$ & $\mathrm{Q}_{\text {pred }}(\mathrm{mg} / \mathrm{g})$ & Err\% \\
\hline \multicolumn{7}{|l|}{ Acetone } \\
\hline TEOS/CO-890 & 1.964 & $5.18 \quad 10^{-5}$ & 0.997 & 600 & 630 & 5.00 \\
\hline TEOS/Brij98 & 2.143 & $0.08 \quad 10^{-5}$ & 0.995 & 450 & 422 & 6.22 \\
\hline 13X/Brij98 & 1.949 & $0.1010^{-5}$ & 0.997 & 700 & 698 & 0.28 \\
\hline \multicolumn{7}{|l|}{ 1-propanol } \\
\hline TEOS/CO-890 & 1.985 & $3.0510^{-5}$ & 0.994 & 520 & 548 & 5.31 \\
\hline TEOS/Brij98 & 2.116 & $1.3410^{-5}$ & 0.982 & 300 & 262 & 12.6 \\
\hline \multicolumn{7}{|l|}{ Carbon dioxide } \\
\hline TEOS/CO-890 & 1.551 & $2.6910^{-4}$ & 0.996 & 150 & 144 & 0.04 \\
\hline TEOS/DM-970 & 1.605 & $2.7010^{-4}$ & 0.995 & 310 & 296 & 0.05 \\
\hline TEOS/Brij98 & 1.648 & $2.1910^{-4}$ & 0.975 & 200 & 202 & 0.01 \\
\hline TEOS/Triton & 1.855 & $2.3010^{-4}$ & 0.990 & 250 & 246 & 0.02 \\
\hline Zeol-13X & 1.661 & $5.6210^{-4}$ & 0.994 & 260 & 284 & 8.41 \\
\hline Zeol- $^{\mathrm{a}}$ & 1.790 & $2.6810^{-4}$ & 0.981 & 460 & 465 & 1.07 \\
\hline 13X/Brij98 & 1.140 & $11.810^{-4}$ & 0.988 & 108 & 142 & 31.5 \\
\hline 3A/Brij98 & 1.140 & $7.4610^{-4}$ & 0.980 & 700 & 846 & 17.3 \\
\hline
\end{tabular}




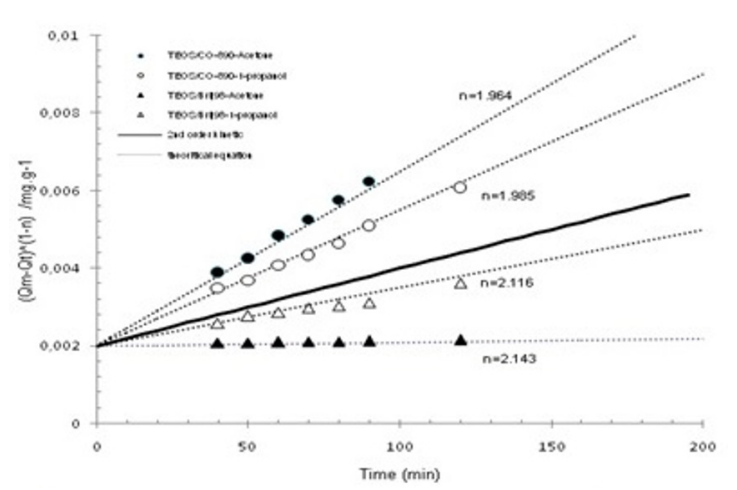

Figure 6. Acetone and 1-propanol kinetics adsorption onto purely silica at 298K (solid points: experimental; dashed lines: model)

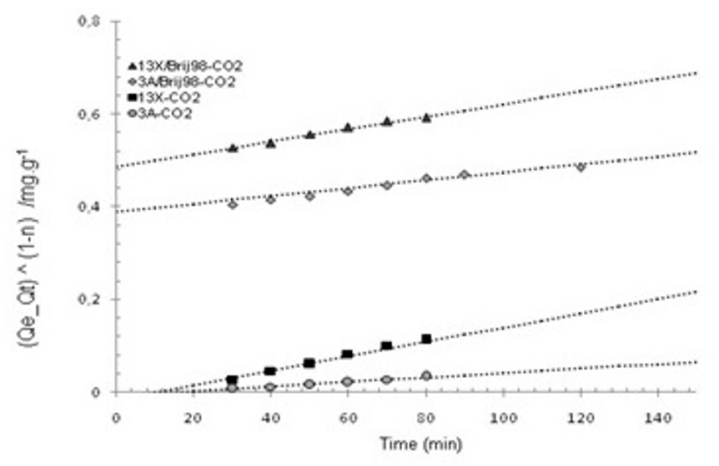

Figure 7. Carbon dioxide kinetics adsorption onto purely silica at 298K (solid points: experimental; dashed lines: model)

Table 3 shows the values of the kinetic constants and the characteristic parameters, along with the coefficient of determinations $\mathrm{R}^{2}$ and percentage deviations Err\%. The values of pseudo order kinetics $\mathrm{n}$ are close to 2 for the adsorption of acetone and 1-propanol in all used sorbents; the linear form of the kinetic model, which shows by extrapolation of the experimental values, a point of convergence of lines corresponding to the value fixed to $\mathrm{Q}_{\mathrm{e}}=500 \mathrm{mg} / \mathrm{g}$ and from which the value of the pseudo-order $\mathrm{n}$ is derived by calculation for acetone and 1-propanol (Figure 6); Probably the lateral interactions of these both polar molecules allow a greater diffusion towards the surface and hence a more substantial adsorption.

Whereas, in adsorption of carbon dioxide values of pseudo-order range between 1.5 and 1.8, but not for modified zeolites, where they close to 1; the quadrupole moment of $\mathrm{CO}_{2}$ rather marked facilitates individual approach for each molecule to the solid surface. The linear form of the kinetic equation, applied to the adsorption in zeolites indicates a large gap in the straight traced between the original and modified zeolites respectively (figure 7); the percentage error is therefore quite high. This suggests probably that the rates of desorption and adsorption of $\mathrm{CO}_{2}$ molecule are equivalent in large pores open to their extremities, unlike microporous surface, wherein the adsorption rate prevails.

Otherwise, theoretical model applies very well to in most kinetics given the values of the criterion $\mathrm{R}^{2}$, with a higher constant rate in the modified zeolites and pseudo-order of the kinetics according to the light organic molecules that adsorb well in the materials studied.

\section{Conclusions}

Spherical mesoporous silica particles were synthesized by using non-ionic surfactants as template, tetraethylorthosilicate and zeolites as silica precursor. Textural characterization shows a high specific surface and large pores for samples, especially for those obtained with zeolites $13 \mathrm{X}$ and $3 \mathrm{~A}$, which are characterized by a high mesoporisity. Samples exhibit a better acetone, 1-propanol and $\mathrm{CO}_{2}$ adsorption at $298 \mathrm{~K}$. This study presents a kinetic analysis of organic compounds adsorption and the proposed model was in good agreement with experimental data.

\section{Acknowledgment}

This work is part of research project CNEPRU (Oran University) of the Ministry of Higher Education which has provided us with financial support; the financial support of the General Directorate of Scientific Research and Technological Development (DGRSDT). The University of Almeria is gratefully acknowledged for characterization analyzes reported in this work.

\section{References}

1. Ruddy EN, Carroll LA. Select the best VOC control strategy. Chemical Engineering. Progress. 1993;89(7):28-35.

2. Braeuer P, Salem M, Harting P, Quitzsch K. Calculation of single adsorption isotherms from gravimetrically measured binary gas mixture adsorption isotherms on activated carbon at high pressures. Separation and Purification Technology. 1997;12(3):255-263.

3. Khan FK, Ghosal AK. Removal of Volatile Organic Compounds from polluted air. Journal of Loss Prevention in the Process Industries. 2000;13(6):527-545.

4. Guillemot M, Mijoin J, Mignard S, Magnoux P. Adsorption of Tetrachloroethylene on Cationic X and Y Zeolites: Influence of Cation Nature and of Water Vapor. Industrial \& Engineering Chemistry Research. 2007;46(13):4614-4620.

5. Serrano DP, Calleja G, Botas JA, Gutierrez FJ. Adsorption and Hydrophobic Properties of Mesostructured MCM-41 and SBA-15 Materials for Volatile Organic Compound Removal. Industrial \& Engineering Chemistry Research. 2004;43(22):7010-7018.

6. Hu Q, Li JJ, Hao ZP, Li LD, Qiao SZ. Dynamic adsorption of volatile organic compounds on organofunctionalized SBA- 
15 materials. Chemical Engineering Journal. 2009;149(13):281-288.

7. Kosuge K, Kubo S, Kikukawa N, Takemori M. Effect of pore structure in mesoporous silicas on VOC dynamic adsorption/ desorption performance. Langmuir. 2007;23(6):3095-3102.

8. Piwonski I, Zajac J, Jones DJ, Rozière J, Partyka S, Plaza S. Adsorption of [60] Fullerene from Toluene Solutions on MCM-41 Silica: A Flow Microcalorimetric Study. Langmuir. 2000;16(24):9488-9492.

9. Tong WY, Kong DJ, Liu ZC, Guo YL, Fang DY. Synthesis and Characterization of ZSM-5/Silicalite-1 Core-Shell Zeolite with a Fluoride-Containing Hydrothermal System. Chinese Journal of Catalysis. 2008;29(12):1247-1252.

10. Wang J, Xu F, Xie WJ, Mei ZJ, Zhang QZ, Cai J, et al. The enhanced adsorption of dibenzothiophene onto cerium/ nickel-exchanged zeolite Y. Journal of Hazardous Materials. 2009;163(2-3):538-543.

11. Kresge CT, Leonowicz ME, Roth WJ, Vartuli JC, Beck JS. Ordered mesoporous molecular sieves synthesized by a liquid-crystal template mechanism. Nature. 1992;359:710-712.

12. Beck JS, Vartuli JC, Roth WJ, Leonowicz ME, Kresge CT, Schmitt KD, et al. A new family of mesoporous molecular sieves prepared with liquid crystal templates. Journal of the American Chemical Society. 1992;114(27):10834-10843.

13. Ryoo R, Kim JM, Shin HJ, Lee JY. Synthesis and hydrothermal stability of a disordered mesoporous molecular sieve. Studies in Surface Science and Catalysis. 1997;105:45-52.

14. Bagshaw SA, Prouzet E, Pinnavaia TJ. Templating of Mesoporous Molecular Sieves by Nonionic Polyethylene Oxide Surfactants. Science. 1995;269(5228):1242-1244.

15. Huo Q, Margolese DI, Stucky GD. Surfactant Control of Phases in the Synthesis of Mesoporous Silica-Based Materials. Chemistry of Materials. 1996;8(5):1147-1160.

16. Richer R, Mercier L. Direct Synthesis of Functional Mesoporous Silica by Neutral pH Nonionic Surfactant Assembly: Factors Affecting Framework Structure and Composition. Chemistry of Materials. 2001;13(9):2999-3008.

17. Zhang W, Pauly TR, Pinnavaia TJ. Tailoring the Framework and Textural Mesopores of HMS Molecular Sieves through an Electrically Neutral $\left(\mathrm{S}^{\circ} \mathrm{I}^{\circ}\right)$ Assembly Pathway. Chemistry of Materials. 1997;9(11):2491-2499.

18. Lagergren SY. Zur theorie der sogenannten adsorption gelöster stoffe. Handligar. 1898;24(4):1-39.

19. Lopes ECN, Anjos FSC, Vieira EFS, Cestari AR. An alternative Avrami equation to evaluate kinetic parameters of the interaction of $\mathrm{Hg}(\mathrm{II})$ with thin chitosan membranes. Journal of Colloid and Interface Science. 2003;263(2):542-547.

20. Pauly TR, Pinnavaia TJ. Pore Size Modification of Mesoporous HMS Molecular Sieve Silicas with Wormhole Framework Structures. Chemistry of Materials. 2001;13(3):987-993.

21. Tao Y, Kanoha H, Hanzawa Y, Kaneko K. Template synthesis and characterization of mesoporous zeolites. Colloids and Surfaces A: Physicochemical and Engineering Aspects. 2004;241(1-3):75-80.

22. Baran R, Millot Y, Onfroy T, Krafft JM, Dzwigaj S. Influence of the nitric acid treatment on $\mathrm{Al}$ removal, framework composition and acidity of BEA zeolite investigated by XRD, FTIR and NMR. Microporous and Mesoporous Materials. 2012;163:122-130.

23. Goto Y, Fukushima Y, Ratu P, Imada Y, Kubota Y, Sugi Y, et al. Mesoporous Material from Zeolite. Journal of Porous Materials. 2002;9(1):43-48.

24. Kim SS, Pauly TR, Pinnavaia TJ. Non-ionic surfactant assembly of wormhole silica molecular sieves from water soluble silicates. Chemical Communications. 2000;10:835-836.

25. Zhang W, Qu Z, Li X, Wang Y, Ma D, Wu J. Comparison of dynamic adsorption/desorption characteristics of toluene on different porous materials. Journal of Environmental Sciences. 2012;24(3):520-528.

26. Fripiat JJ, Cruz MI, Bohor BF, Thomas J Jr. Interlamellar adsorption of carbon dioxide by smectites. Clays and Clay Minerals. 1974;22(1):23-30.

27. Lee KB, Beaver MG, Caram HS, Sircar S. Reversible chemisorptions of carbon dioxide: simultaneous production of fuel-cell grade $\mathrm{H}_{2}$ and compressed $\mathrm{CO}_{2}$ from synthesis gas. Adsorption. 2007;13(3):385-397.

28. Chew TL, Ahmad AL, Bhatia S. Ordered mesoporous silica (OMS) as an adsorbent and membrane for separation of carbon dioxide $\left(\mathrm{CO}_{2}\right)$. Advances in Colloid and Interface Science. 2010;153(1-2):43-57.

29. Hwang KS, Han L, Park DW, Oh KJ, Kim SS, Park SW. Adsorption of carbon dioxide onto PDA-CP-MS41 adsorbent. Korean Journal of Chemical Engineering. 2010;27(1):241-248. 